\title{
Repair Optimization of Highway Bridges Using System Reliability APPROACH
}

\author{
By Allen C. Estes, ${ }^{1}$ Member, ASCE, and Dan M. Frangopol, ${ }^{2}$ Fellow, ASCE
}

\begin{abstract}
As reliability based methods gain increased acceptance, there is greater opportunity to use scarce resources more efficiently while maintaining a prescribed level of reliability of a structure throughout its service life. The goal is to provide management decisions that will balance lifetime system reliability and expected lifecycle cost in an optimal manner. This study proposes a system reliability approach for optimizing the lifetime repair strategy for highway bridges. The approach is demonstrated using an existing Colorado State highway bridge. The bridge is modeled as a series-parallel combination of failure modes, and the reliability of the overall bridge system is computed using time-dependent deterioration models and live load models. Based on an established repair criterion, available repair options, repair costs, and updating, the optimum lifetime repair strategy is developed. The sensitivity of the optimum strategy to changes in various problem parameters including the prescribed service life, system failure criterion, and net discount rate is studied. Finally, the conclusions reveal that the proposed approach demonstrates real potential for practical applications, needs frequent updates through inspection, and requires considerable research effort to develop accurate input data.
\end{abstract}

\section{INTRODUCTION}

Over the last decade, structural reliability based analysis and design methods have become widely accepted among researchers and increasingly acknowledged among practicing engineers. As reliability concepts are better understood and more software is developed, reliability based applications are transitioning from simple, hypothetical examples using fictitious data to more complex, practical, and realistic engineering problems. One area where structural optimization and system reliability methods show great promise is the management of decaying civil infrastructure systems. In countries with strong economies, the importance of life-cycle cost-effectiveness in the analysis of decisions related to the inspection, repair, upgrading, replacement, and even shut down of existing constructed facilities is being increasingly recognized (Chang and Shinozuka 1996; Frangopol et al. 1998). Reliability based methods provide the rational approach to use scarce resources efficiently while maintaining a prescribed level of reliability of a structure throughout its designated service life.

This study proposes a system reliability based approach for optimizing the lifetime repair strategy for highway bridges. The approach is demonstrated using an existing Colorado State highway bridge located in the Denver metropolitan area. The bridge is modeled as a series-parallel combination of failure modes and a computer program is used to calculate reliability of the bridge system. Time-dependent deterioration models that include corrosion of the bridge girders and chloride penetration in the concrete deck are considered, along with a model that accounts for the increase in live load over time. A repair criterion is established where the bridge must be repaired whenever the reliability of the system falls below a prescribed target value. Various repair options and their associated costs were developed in conjunction with the Colorado Department of Transportation. The optimum lifetime repair strategy is found by examining all feasible combinations of these options and considering the service life of the bridge.

${ }^{1}$ Lt. Col., U.S. Army Corps of Engrs., 169th Engr. Battalion, Fort Leonard Wood, MO 65473; formerly, Grad. Student, Dept. of Civ., Envir., and Arch. Engrg., Univ. of Colorado, Boulder, CO 80309-0428.

${ }^{2}$ Prof., Dept. of Civ., Envir., and Arch. Engrg., Univ. of Colorado, Campus Box 428, Boulder, CO.
The optimum repair strategy varies with the desired period of service life and is based on a number of assumptions. The strategy must be updated over time as the results of both biennial visual inspections and specific nondestructive evaluation (NDE) testing become available.

\section{METHODOLOGY}

The general methodology for optimizing the bridge repair strategy consists of the following steps.

- Identify the relevant failure modes of the bridge. Decide which variables are random in nature and find the parameters (e.g., mean, standard deviation) associated with these random variables. Develop limit-state equations in terms of these random variables for each failure mode. Compute the reliability with respect to the occurrence of each possible failure mode.

- Develop a system model of the overall bridge as a seriesparallel combination of individual failure modes. Compute the system reliability of the bridge.

- Develop deterioration and live-load models that describe how the structure and its environment are expected to change over time. This will inevitably introduce new random variables. Compute the system reliability of the structure over time.

- Establish a repair or replacement criterion. Develop repair options and their associated costs.

- Using all feasible combinations of the repair options and the expected life of the structure, optimize the repair strategy by minimizing total lifetime repair cost while maintaining the prescribed level of reliability.

- Develop a lifetime inspection program to provide the necessary information to update the optimum repair strategy over time.

This methodology is applicable to any type of bridge. It was applied to several truss bridges using hypothetical data (Estes 1997) with promising results. The methodology was then tested on an existing structure, specifically State Highway Bridge E-17-AH, located in Denver.

\section{COLORADO BRIDGE E-17-AH}

Colorado Bridge E-17-AH has three simple spans of equal length $(13.3 \mathrm{~m})$ and a total length of $42.1 \mathrm{~m}$ as shown in Fig. 1. The deck consists of $22.9 \mathrm{~cm}$ of reinforced concrete and a $7.6-\mathrm{cm}$ surface layer of asphalt. The east-west bridge has two 


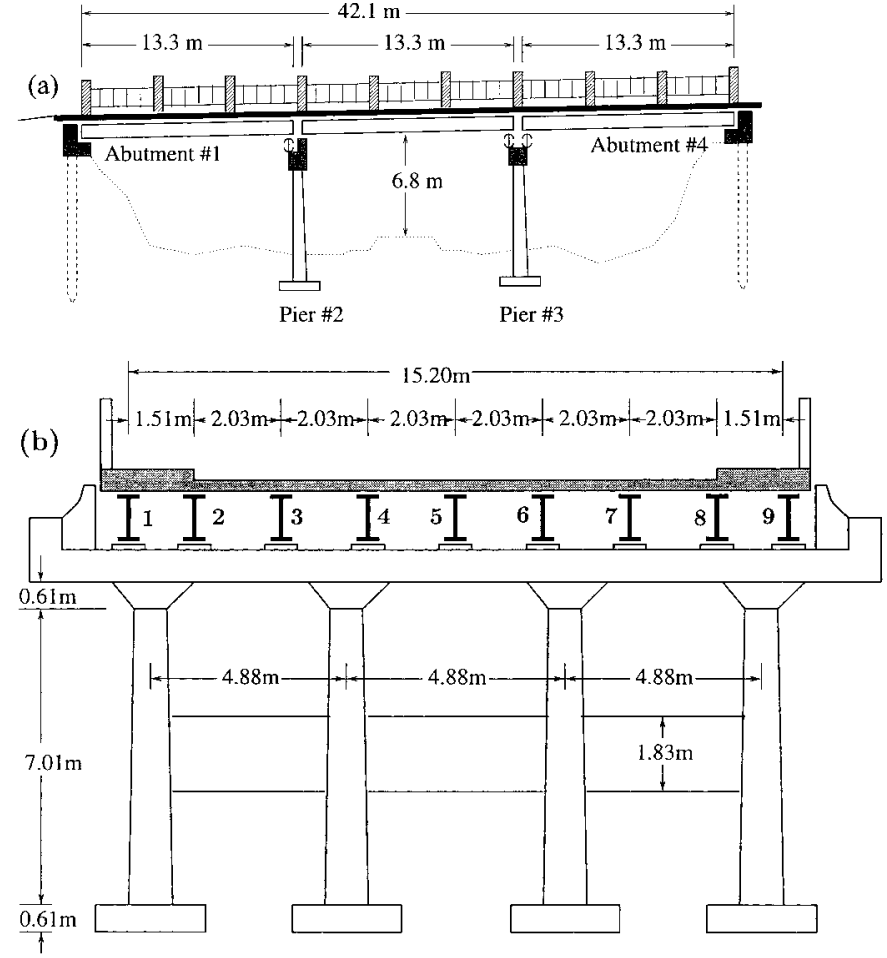

FIG. 1. Colorado State Highway Bridge E-17-AH: (a) Elevation; (b) Cross Section

lanes of traffic in each direction with an average daily traffic of 8,500 vehicles. The roadway width is $12.18 \mathrm{~m}$ with 1.51 $\mathrm{m}$ pedestrian sidewalks and handrailing on each side. The bridge offers $6.8 \mathrm{~m}$ of clearance for the railroad spur that runs underneath. There is no skew or curvature. The slab is supported by nine standard-rolled, compact, noncomposite steel girders as shown in Fig. 1(b). The girders are stiffened by end diaphragms and intermediate diaphragms at the third points. Each girder is supported at one end by a fixed bearing and an expansion bearing at the other end.

\section{COMPONENT RELIABILITY}

Colorado Bridge E-17-AH was analyzed with respect to the possible occurrence of 16 different failure modes, as listed in Table 1 . Each failure mode $i$ is described by a limit state $g(i)$ $=0$, such that $g(i) \leq 0$ defines the failure state, and $g(i)>0$ defines the safe state. The failure modes include moment fail-

TABLE 1. Failure Mode, Limit State Equation, and Reliability Index

\begin{tabular}{l|c|c}
\hline \hline \multicolumn{1}{c|}{ Failure mode } & $\begin{array}{c}\text { Limit-state } \\
\text { equation } \\
(1)\end{array}$ & $\begin{array}{c}\text { Reliability } \\
\text { index } \beta \\
(3)\end{array}$ \\
\hline Concrete deck, flexure & $g(1)=0$ & 5.51 \\
Interior girder, shear & $g(2)=0$ & 6.22 \\
Interior girder, flexure & $g(3)=0$ & 2.44 \\
Exterior girder, flexure & $g(4)=0$ & 4.02 \\
Exterior girder, shear & $g(5)=0$ & 7.13 \\
Interior-exterior girder, flexure & $g(6)=0$ & 2.79 \\
Interior-exterior girder, shear & $g(7)=0$ & 6.43 \\
Pier cap, shear & $g(8)=0$ & 3.83 \\
Pier cap, positive moment & $g(9)=0$ & 8.82 \\
Pier cap, negative moment & $g(10)=0$ & 8.75 \\
Top column, crushing & $g(11)=0$ & 5.80 \\
Bottom column, crushing & $g(12)=0$ & 5.72 \\
Footing, one-way shear & $g(13)=0$ & 7.69 \\
Footing, two-way shear & $g(14)=0$ & 5.28 \\
Footing, flexure & $g(15)=0$ & 2.60 \\
Expansion bearing, crushing & $g(16)=0$ & 7.84 \\
\hline \hline
\end{tabular}

ure of the slab, moment and shear failure of the girders, and multiple failure modes of the pier cap, columns, and footings. Limit-state equations for all failure modes in terms of the random variables were developed. The girders were classified as exterior [i.e., girders 1 and 9 in Fig. 1(b)] that carry pedestrian traffic and emergency vehicle use, interior-exterior [i.e., girders 2 and 8 in Fig. 1(b)] that act as exterior girders for normal traffic, and interior [i.e., girders 3 to 7 in Fig. 1(b)]. Limitstate equations were developed separately for each type of girder.

Prior to considering any deterioration, 24 random variables were identified that included material strength, model uncertainty, girder distribution factors, and material dimensions that could not be directly measured. The parameters that define these random variables were taken from the existing literature. The notations used to define these random variables and their mean values and standard deviations are shown along with the pertinent references in Table 2 .

Limit-state equations that define the capacity minus demand for each of the 16 failure modes in Table 1 were developed in terms of the 24 random variables in Table 2 [for the details see Estes (1997)]. The limit-state equation for the moment failure of the slab $g(1)=0$, for example, is

$$
\begin{aligned}
& g(1)=M_{\text {Capacity }}-M_{\text {Demand }}=\gamma_{m f c}\left[0.349 \lambda_{\text {rebar }} f_{y} \lambda_{d_{\text {eff }}}\right. \\
& \left.-\frac{0.3844 \lambda_{\text {rebar }}^{2} f_{y}^{2}}{244.8 f_{c}^{\prime}}\right]-0.137 \lambda_{\text {asph }}-0.471 \lambda_{\text {conc }} \\
& -4.26 \lambda_{\text {trk }}=0
\end{aligned}
$$

The limit-state equations for shear $g(2)=0$ and moment $g(3)$ $=0$ in the interior girders, respectively, are

$$
\begin{aligned}
& g(2)=V_{\text {Capacity }}-V_{\text {Demand }}=10.55 F_{y} \gamma_{m s g}-18.04 \lambda_{\text {conc }} \\
& \quad-5.26 \lambda \text { asph }-2.89 \lambda_{\text {steel }}-28.33 V_{\text {trk-i }} D F_{i} I_{\text {beam }}=0 \\
& g(3)=M_{\text {Capacity }}-M_{\text {Demand }}=39.8 F_{y} \gamma_{m f g}-197.65 \lambda_{\text {conc }} \\
& \quad-57.64 \lambda_{\text {asph }}-31.7 \lambda_{\text {steel }}-M_{\text {trk-i }} D F_{i} I_{\text {beam }}=0
\end{aligned}
$$

The other limit-state equations for shear and moment in the other girders and for various failure modes in the substructure and bearings are given in Estes (1997). Based on these limitstate equations, the reliability with respect to the occurrence of each possible failure mode was computed separately using a first-order reliability method approach. All random variables were transformed to uncorrelated standard normal variables and an iterative search technique was used to compute the reliability index $\beta$. The reliability index for each failure mode considered is indicated in Table 1. The reliabilities shown in Table 1 are based on the projected 50-year live load model developed by Nowak (1993). The choice of a live load model had a large effect on the reliability results. Considering, for example, the failure mode of an interior girder in flexure, $g(3)$ $=0$, the associated reliability index using the 50-year model (Nowak 1993) was $\beta=2.44$. For the same failure mode, the reliability index was $\beta=4.00$, using a deterministic HS-20 truck for the live load. Finally, using the 50-year live load from the model developed by Ghosn and Moses (1984), the reliability index was $\beta=3.86$ for low traffic volume and $\beta=$ 3.56 for medium traffic volume.

In addition, a complete sensitivity analysis was performed on all random variables used in the limit-state equations. The variables with the most effect on the reliability index were consistently the mean values of the material strengths and the model uncertainties, both of which appear on the capacity side of the limit-state equation. The sensitivity results help identify those variables for which further research would be the best investment. 


\begin{tabular}{|c|c|c|c|}
\hline $\begin{array}{l}\text { Definition and units of random variables } \\
\text { (1) }\end{array}$ & $\begin{array}{l}\text { Notation } \\
\text { (2) }\end{array}$ & $\begin{array}{c}\text { Mean value and } \\
\text { standard deviation } \\
\text { (3) }\end{array}$ & $\begin{array}{l}\text { Reference } \\
\quad(4)\end{array}$ \\
\hline $\begin{array}{l}\text { Uncertainty factor: reinforcing steel area in concrete } \\
\text { Yield stress of steel reinforcing in deck (MPa) } \\
\text { Uncertainty factor: effective depth of rebar in concrete } \\
\text { Model uncertainty: flexure in concrete } \\
\text { Uncertainty factor: weight of truck on bridge } \\
\text { Uncertainty factor: live load shear on interior girders } \\
\text { Yield strength of steel in girders (MPa) } \\
\text { Uncertainty in live load girder distribution: interior girders } \\
\text { Uncertainty in live load girder distribution: interior-exterior girders } \\
\text { Uncertainty in live load girder distribution: exterior girders } \\
\text { Uncertainty factor: impact on girders } \\
\text { Live load moment on interior girders }(\mathrm{kNm}) \\
\text { 28-day compressive strength of concrete (MPa) } \\
\text { Uncertainty factor: weight of asphalt } \\
\text { Uncertainty factor: weight of concrete } \\
\text { Uncertainty factor: weight of steel } \\
\text { Model uncertainty: shear in steel } \\
\text { Model uncertainty: flexure in steel } \\
\text { Uncertainty factor: live load shear on exterior girders } \\
\text { Live load moment on exterior girders (kNm) } \\
\text { Model uncertainty: shear in concrete } \\
\text { Area of shear reinforcement/bar spacing (mm) } \\
\text { Model uncertainty: eccentricity in short columns } \\
\text { Modulus of elasticity: steel (GPa) }\end{array}$ & $\begin{array}{l}\lambda_{\text {rebar }} \\
f_{y} \\
\lambda_{d_{\text {eff }}} \\
\gamma_{\text {mfc }} \\
\gamma_{\text {trk }} \\
V_{\text {trk-i }} \\
F_{y} \\
D F_{i} \\
D F_{i-e} \\
D F_{e} \\
I_{\text {beam }} \\
M_{\text {trk-i }} \\
f_{c}^{\prime} \\
\lambda_{\text {asph }} \\
\lambda_{\text {conc }} \\
\lambda_{\text {steel }} \\
\gamma_{m s g} \\
\gamma_{m f g} \\
V_{\text {trk-e }} \\
M_{\text {trk-e }} \\
\gamma_{m s c} \\
A_{v} / s \\
\gamma_{\text {mcc }} \\
E_{s}\end{array}$ & $\begin{array}{l}(1.0 ; 0.015)^{\mathrm{b}} \\
(386.1 ; 42.5) \\
(1.0 ; 0.02) \\
(1.02 ; 0.061) \\
(1.38 ; 0.1656) \\
(1.38 ; 0.1656) \\
(252.5 ; 29.0) \\
(1.309 ; 0.163) \\
(1.14 ; 0.142) \\
(0.982 ; 0.122) \\
(1.14 ; 0.114) \\
(579.4 ; 69.6) \\
(19.0 ; 3.42) \\
(1.0 ; 0.25) \\
(1.05 ; 0.105) \\
(1.03 ; 0.082) \\
(1.14 ; 0.137) \\
(1.11 ; 0.128) \\
(1.13 ; 0.1356) \\
(474.1 ; 56.9) \\
(1.075 ; 0.108) \\
(4.52 ; 0.18) \\
(0.85 ; 0.085) \\
(199.9 ; 12.0)\end{array}$ & $\begin{array}{l}\text { Nowak et al. (1994) } \\
\text { Nowak (1993) } \\
\text { Lu et al. (1994) } \\
\text { Nowak and Yamani (1995) } \\
\text { Nowak (1993) } \\
\text { Nowak (1993) } \\
\text { Nowak (1993) } \\
\text { Zokaie et al. (1991) } \\
\text { Zokaie et al. (1991) } \\
\text { Zokaie et al. (1991) } \\
\text { Nowak et al. (1994) } \\
\text { Nowak (1993) } \\
\text { Nowak et al. (1994) } \\
\text { Nowak (1993) } \\
\text { Nowak (1993) } \\
\text { Nowak (1993) } \\
\text { Nowak (1993) } \\
\text { Nowak (1993) } \\
\text { Nowak (1993) } \\
\text { Nowak (1993) } \\
\text { Nowak and Yamani (1995) } \\
\text { Lu et al. (1994) } \\
\text { Nawy (1990) } \\
\text { Tabsh and Nowak (1991) }\end{array}$ \\
\hline
\end{tabular}

\section{SYSTEM RELIABILITY}

To compute the reliability of a system, there needs to be a model that describes the behavior of the system and the relationship of the individual components to the overall system. Considering all possible failure modes, the series-parallel model for Bridge E-17-AH is shown in Fig. 2. In this figure, the failure functions $g(i)$ associated with the individual failure modes correspond to the limit-state equations $g(i)=0$, indicated in Table 1. For example, $g(1)$ refers to failure of the concrete bridge deck that is shown in series in Fig. 2. Because of the large end and center diaphragms in the superstructure, which will transfer load, it is assumed that the failure of any three adjacent girders is required for the superstructure to fail and that the concrete deck is identical throughout an individual span. Using the 50-year live load model (Nowak 1993), assuming no deterioration of the structure over time, and considering no correlation between the resistances of the girders, the system reliability for the bridge was $\beta_{\mathrm{sys}}=2.51$.

The bridge reliability was computed using RELSYS (RELiability of SYStems), a FORTRAN 77 computer program developed by Estes and Frangopol (1998). RELSYS first computes the reliability of all components in a series-parallel system. The system is progressively reduced to equivalent components until a single equivalent component remains. Series and parallel systems are solved separately and equivalent alpha vectors are used to account for the correlation between failure modes.

It is possible to simplify this model further by making some reasonable assumptions. Those failure modes with very high reliabilities (e.g., $\beta_{i}>6.00$ ), which contribute little to the reliability of the system, are eliminated. Further, if the spans are assumed to be perfectly correlated, and the symmetry within a span is considered, the system model can be reduced to the model shown in Fig. 3(a), where any three adjacent girders must still fail for the system to fail. The girders are numbered $1-5$ as shown in Fig. 1(b). Using the simplified model in Fig. 3(a) without deterioration, the system reliability was equal to $\beta_{\mathrm{sys}}=2.54$, which is very close to the reliability index $\beta_{\mathrm{sys}}=$ 2.51 of the more complex model shown in Fig. 2.
The system model and the correlation between random variables will affect the overall bridge reliability. In the previous computation where $\beta_{\text {sys }}=2.54$, it was assumed that the girder resistances were uncorrelated, $\rho_{R_{i}, R_{j}}=0.0$, where $\rho_{R_{i}, R_{j}}$ is the correlation coefficient between the resistance of girders $i$ and $j$. Using the model in Fig. 3(a), the system reliability was $\beta_{\text {sys }}$ $=2.49$ when the resistance correlation was $\rho_{R_{i}, R_{j}}=0.5$ and $\beta_{\text {sys }}$ $=2.31$ when $\rho_{R_{i} R_{j}}=1.0$. The system failure event was changed as shown in Fig. 3(b), where only any two adjacent girders need to fail for the system to fail, and in Fig. 3(c), where only one girder must fail. The system reliability results for all three models shown in Fig. 3 are indicated in Table 3.

For the model in Fig. 3(c), which is entirely a series system, the increased correlation between the resistances improves the system reliability. For the series-parallel system models in Figs. 3( $\mathrm{a}$ and $\mathrm{b})$, the increased correlation between the resistances decreases the system reliability. When there is perfect correlation between the resistances, the three models produce very close results. The effects of correlation between other random variables on bridge system reliability could also be investigated along with other variations in the system model. Such analyses emphasize the importance of accurate input data for reliability computations. The results obtained are only as good as the parameters of the random variables, the correlation structure among variables, and the system model that produces them.

\section{TIME EFFECT ON BRIDGE RELIABILITY}

The reliability of a bridge is only valid for a specific point in time. The maximum value of the live load is expected to increase over time, and the bridge deteriorates through aging, increased use, and specific mechanisms such as fatigue and corrosion. This study considers only corrosion of the girders and chloride penetration of the concrete deck and pier cap as deterioration mechanisms.

The live load model used in this study (Nowak 1993) accounts for the increased effects of maximum shear and moment as more trucks pass over the bridge. This model is based on statistics of extreme values where the probability of en- 


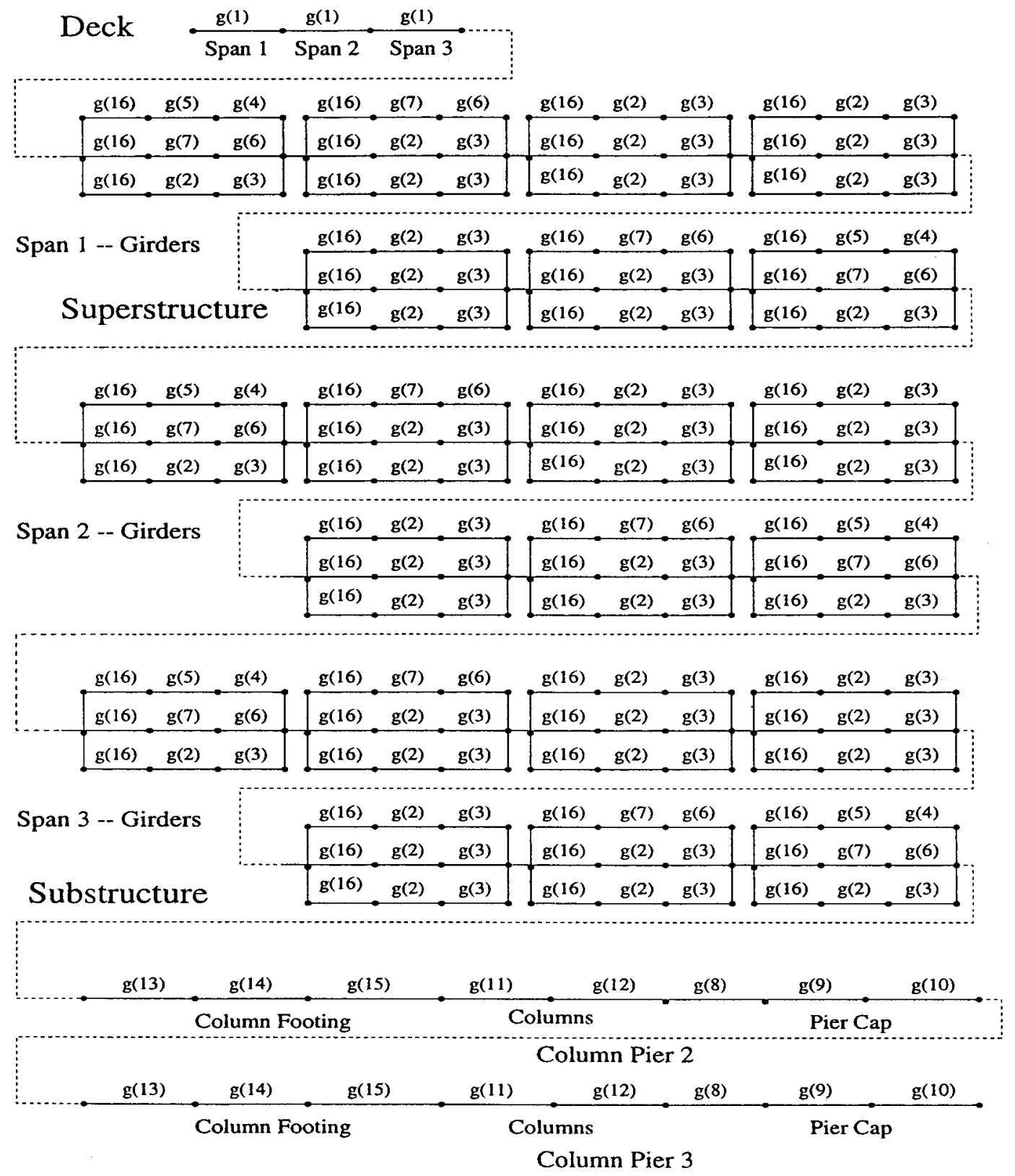

FIG. 2. Series-Parallel Model for Bridge E-17-AH: Deck, Superstructure, and Substructure

countering a large truck at the extreme upper tail of the distribution increases as the number of trucks passing over the bridge increases. The load model uses the actual daily truck traffic, and the actual bridge span lengths to predict the maximum moment and shear effects over time in Bridge E-17-AH. The time-dependent mean maximum moment in the interior girders is shown in Fig. 4. Similar graphs for mean maximum shear, and standard deviations of maximum moment and shear for all types of girders shown in Fig. 1(b), were developed by Estes (1997).

The corrosion of the girders was predicted using regression analysis of the field results in 46 locations. Based on these results a corrosion propagation model was developed that predicts the average corrosion penetration $C(t)$ in micrometers $\left(10^{-6} \mathrm{~m}\right)$ at any time $t$ (in years). The bridge girders are carbon steel. Because the interior girders are clearly corroding at a lesser rate than the exterior and interior-exterior girders, two environments were defined to account for the different observed corrosion rates (i.e., Environment 1 corresponds to exterior and interior-exterior girders, and Environment 2 corresponds to interior girders). For each environment considered, the mean values, standard deviations, and correlation of random variables used to predict corrosion are given in Estes (1997).

The assumed corrosion pattern for the girders is shown in Fig. 5, where the corrosion extends all the way up the web at the supports and only a quarter of the way up the web at the center. Because moment is critical at the center of the simple span, the deterioration of the plastic section modulus $Z$ is computed over time. This is shown in Fig. 6 for both the mean value $\bar{Z}$ and the standard deviation $\sigma(Z)$ of the plastic section modulus at the center of an interior-exterior girder over a 70year time period. Similar graphs show the deterioration of the web area at the span supports where shear is critical (Estes 1997).

Meanwhile, it is assumed that chlorides from road salts are penetrating the concrete of the deck and pier cap. Once the chlorides reach a threshold concentration at the reinforcing steel, corrosion of the reinforcement begins. The moment capacity of the slab is reduced due to area loss of the top reinforcing steel. In this time-dependent study, a variable of interest is the corrosion initiation time $T_{I}$, which is the amount of 


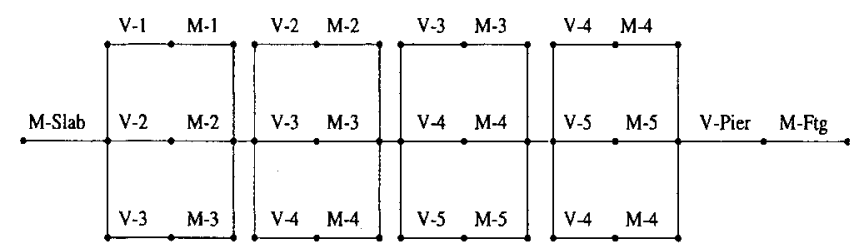

(a)

V-1: Failure Due to Shear in Girder 1

M-3: Failure Due to Moment in Girder 3

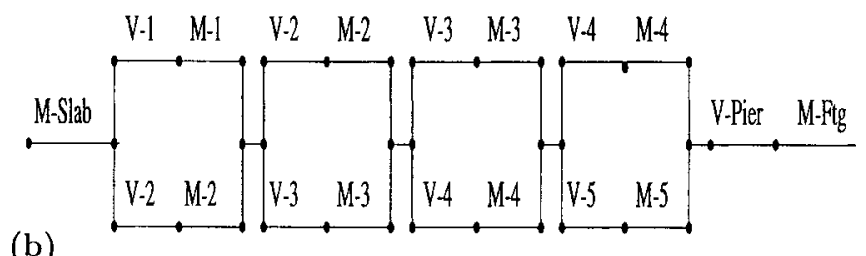

(b)

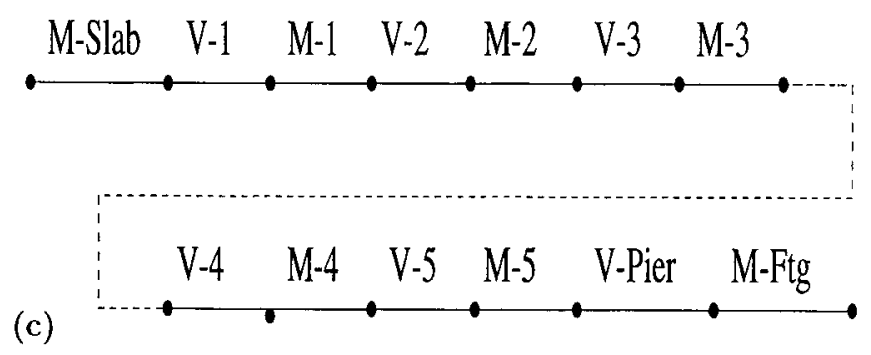

FIG. 3. Simplified Series-Parallel Model for Bridge E-17-AH: (a) Failure of any Three Adjacent Girders Required for System Failure; (b) Failure of any Two Adjacent Girders Required for System Failure; (c) Failure of any Girder Required for System Failure

TABLE 3. Bridge System Reliability Results Using Different System Failure Models (Fig. 3) and Different Correlation between Girder Resistances

\begin{tabular}{c|c|c|c}
\hline \hline \multirow{2}{*}{$\begin{array}{c}\text { System failure event } \\
(1)\end{array}$} & \multicolumn{3}{|c}{ Correlation Between Girder Resistances } \\
\cline { 2 - 4 } & $\begin{array}{c}\rho_{R_{i} R_{j}}=0.0 \\
(2)\end{array}$ & $\begin{array}{c}\rho_{R_{i} R_{j}}=0.5 \\
(3)\end{array}$ & $\begin{array}{c}\rho_{R_{i} R_{j}}=1.0 \\
(4)\end{array}$ \\
\hline $\begin{array}{c}\text { Failure of any girder } \\
\text { Failure of any two } \\
\text { adjacent girders }\end{array}$ & 1.97 & 2.06 & 2.23 \\
$\begin{array}{c}\text { Failure of any three } \\
\text { adjacent girders }\end{array}$ & 2.50 & 2.41 & 2.26 \\
\hline \hline
\end{tabular}

time between the application of the surface chloride and the onset of corrosion (which occurs when the critical chloride concentration $C_{\mathrm{cr}}$ is reached). The corrosion initiation time $T_{I}$ can be expressed as (Thoft-Christensen et al. 1997)

$$
T_{I}=\frac{\left(d_{I}-D_{I} / 2\right)^{2}}{4 D_{c}}\left[\operatorname{erf}^{-1}\left(\frac{C_{\mathrm{cr}}-C_{o}}{C_{i}-C_{o}}\right)\right]^{-2}
$$

where $d_{I}-D_{I} / 2=$ concrete cover; $D_{I}=$ initial diameter of the reinforcement bar; $C_{o}=$ equilibrium chloride concentration on the concrete surface; and $C_{i}=$ initial chloride concentration. Using values for the random variables developed by ThoftChristensen et al. (1997), the mean chloride initiation time for the concrete deck was computed as $\bar{T}_{I}=19.60$ years with a standard deviation of $\sigma\left(T_{I}\right)=7.51$ years. On the pier cap, the mean corrosion initiation time was $\bar{T}_{I}=39.28$ years with a standard deviation of $\sigma\left(T_{I}\right)=21.21$ years. Once corrosion has

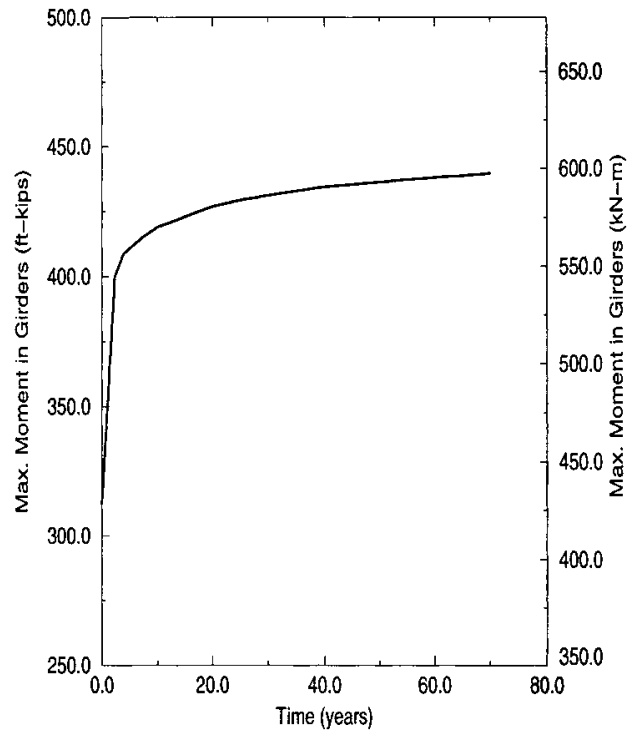

FIG. 4. Mean Maximum Moment over Time for Interior Girders
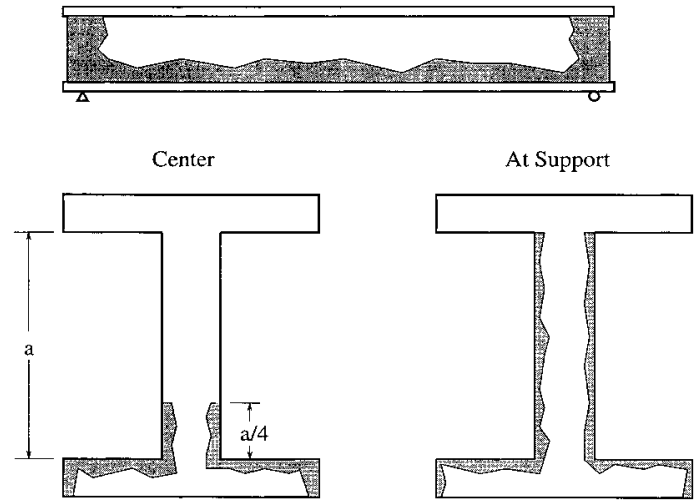

FIG. 5. Corrosion Pattern on Steel Girders

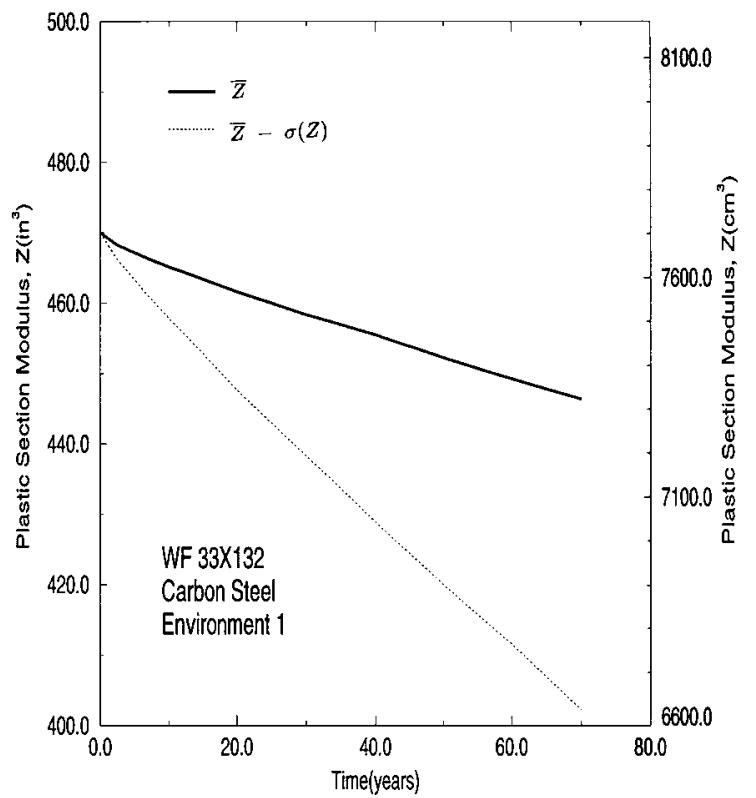

FIG. 6. Deterioration of Plastic Section Modulus $Z$ due to Corrosion at Midspan of Interior-Exterior Girder

started, then the diameter of the reinforcement bars as a function of time $D_{I}(t)$ is modeled as

$$
D_{I}(t)=D_{I}-C_{\text {corr }} i_{\text {corr }}\left(t-T_{I}\right)=D_{I}-0.0203 i_{\text {corr }}\left(t-T_{I}\right)
$$




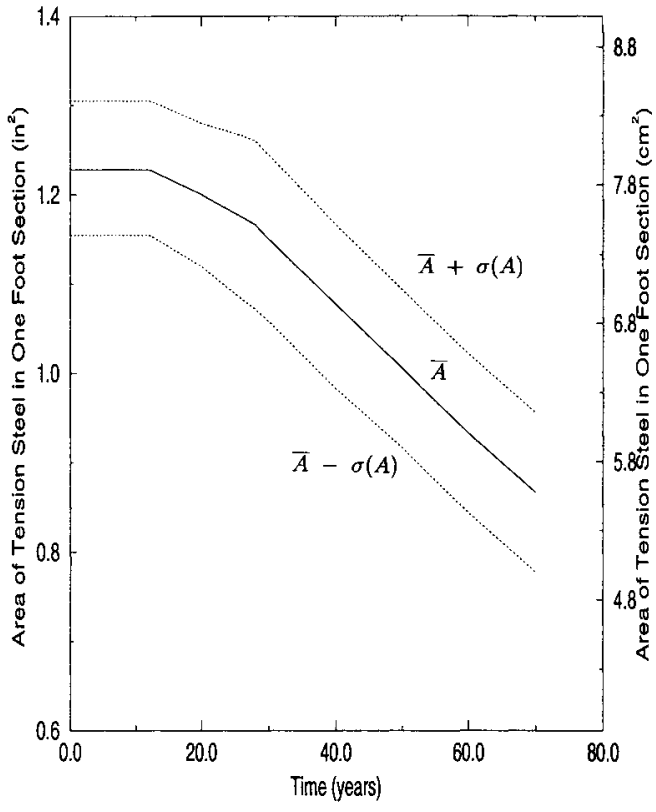

FIG. 7. Deterioration of Area of Reinforcing Steel $\boldsymbol{A}$ in Top of 0.305-m (1-ft) Section of Slab Caused by Chloride Penetration

where $D_{I}=$ initial diameter of the reinforcing bar (in $\mathrm{mm}$ ); $C_{\text {corr }}=$ corrosion coefficient, which for this study is estimated to be $C_{\text {corr }}=0.0203$; and $i_{\text {corr }}=$ parameter related to the rate of corrosion (i.e., mean corrosion rate $=0.0203 \times 2.49 \mathrm{~mm} /$ year $=0.0506 \mathrm{~mm} /$ year$)$. Based on the mean value and standard deviation for the chloride initiation time for the concrete deck, Fig. 7 shows the mean $\bar{A}$ and standard deviation $\sigma(A)$ for the area of the top reinforcing steel $A$ in the deck over a 70-year time period. The graph can clearly be divided into three regions: (1) The initial flat region where there is a high certainty that corrosion has not begun; (2) a second portion where there is uncertainty about whether or not corrosion has been initiated; and (3) a third steeper region where it is very likely that corrosion has begun. With the predicted increase in live load and the expected bridge deterioration defined for any point in time, the system reliability of the bridge can be computed at any point in time.

\section{REPAIR CRITERION AND REPAIR OPTIONS}

The repair criterion is based on the reliability of the bridge system rather than the reliability of any individual component. In this study, the minimum allowable (i.e., target) system reliability of the bridge is prescribed as $\beta_{\min }=2.0$. Anytime the system reliability of the bridge $\beta_{\text {sys }}$ falls below the target value, the bridge must be repaired or replaced.

Given the existing bridge and deterioration models, six realistic options and their 1996 costs were developed in consult with the Colorado Department of Transportation. Using expert opinions from unpublished interviews, historical cost data for actual bridge repairs (Colorado 1994, 1995), and the actual original cost of the bridge ( $\$ 393,000$ in 1942), the options and costs are shown in Table 4, along with the failure functions $g(i)$ affected by the option considered. Option 1 is to replace the entire deck, which would include the concrete slab, sidewalk, guardrails, and a fresh layer of asphalt. Option 2 is to replace the exterior, including interior-exterior girders that are deteriorating faster than the interior girders. This option includes replacement of four girders, sidewalk, guard rails, and only that portion of the slab above the replaced girders. Option 3 is the same as Option 2 except that the entire deck is replaced. Option 4 is to replace all nine girders and the entire
TABLE 4. Replacement Options and Associated Repair Costs

\begin{tabular}{c|l|c|l}
\hline \hline $\begin{array}{c}\text { Option } \\
\text { identification } \\
(1)\end{array}$ & \multicolumn{1}{|c|}{$\begin{array}{c}\text { Option definition } \\
(2)\end{array}$} & $\begin{array}{c}\text { Expected } \\
\text { repair cost } \\
\left(\begin{array}{c}1996 \text { US\$) } \\
(3)\end{array}\right.\end{array}$ & $\begin{array}{c}\text { Failure functions } \\
\text { affected by } \\
\text { intervention } \\
(4)\end{array}$ \\
\hline 0 & $\begin{array}{l}\text { Do nothing } \\
\text { Replace deck } \\
1\end{array}$ & $\begin{array}{l}\text { Replace exterior } \\
\text { girders }\end{array}$ & $\begin{array}{l}\text { None } \\
225,600\end{array}$ \\
3 & $\begin{array}{l}\text { Replace exterior } \\
\text { girders and deck } \\
g(4)-g(7)\end{array}$ & 341,800 & $g(1), g(4)-g(7)$ \\
4 & $\begin{array}{l}\text { Replace } \\
\text { superstructure } \\
\text { Replace entire bridge }\end{array}$ & 487,100 & $g(1)-g(7)$ \\
5 & 659,900 & All \\
\hline
\end{tabular}

${ }^{a}$ Corresponding failure modes associated with failure function $g(i)$ are indicated in Table 1.

deck as described in Option 1. Finally, Option 5 is to replace the entire bridge.

\section{OPTIMUM REPAIR STRATEGY}

An optimum repair strategy can be developed by using all feasible combinations of the options listed in Table 4. Option 2 , for example, was not a feasible alternative, because replacing the exterior girders did not bring the system reliability of the structure above the target reliability level. The various options are tried until replacement of the bridge is the only remaining option. For any specified service-life extension of the bridge, an optimum strategy is determined. The repair criterion $\beta_{\min }=2.0$ is applied to Bridge E-17-AH using the simplified series-parallel model shown in Fig. 3(a), where the correlation between the girder resistances is $\rho_{R_{i}, R_{j}}=0.5$.

Fig. 8 shows the effect of repeatedly replacing the slab (Option 1). The dotted lines show the reliability with respect to each of the nine different failure modes considered in Fig. 3(a), and the solid line is the reliability of the bridge system over time. The top graph shows the system reliability and the reliability of the girders with respect to shear. The shear girder reliabilities are initially very high, but the rapid deterioration of the web area causes the reliabilities of the exterior and in-

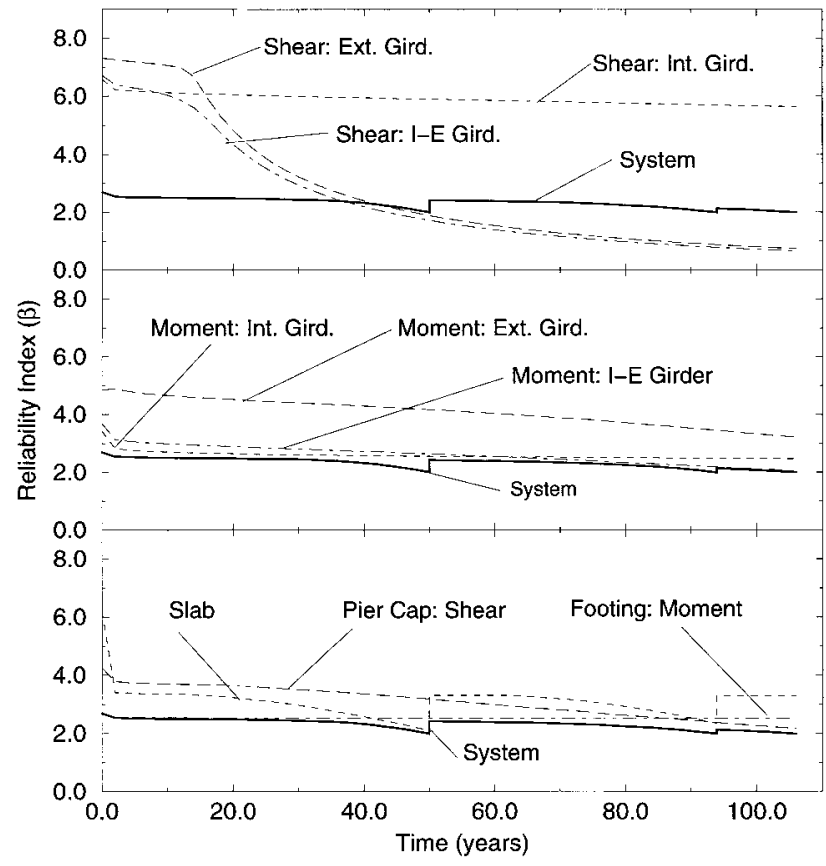

FIG. 8. Deck Replacement Strategy (Option 1) Using Bridge System Failure Model in Fig. 3(a) 
terior-exterior girders to drop quickly. After about 40 years, the reliability of these girders with respect to shear is below the reliability of the system. This occurs because of the parallel nature of the system model. Because any three adjacent girders must fail for the bridge superstructure to fail, the interior girders that are not deteriorating as quickly are contributing to maintain the reliability of the system above the target level.

The middle graph in Fig. 8 shows the system reliability along with the reliability of the three types of girders with respect to moment. The interior girder has the lowest initial reliability, but it has the slowest deterioration rate. In fact, there is a crossover point around 60 years where the reliability of the interior-exterior girder becomes less than that of the interior girder.

The bottom graph in Fig. 8 shows the system reliability and the component reliabilities of the slab, pier cap, and column footing. These components are all in the series portion of the system model and will therefore always reflect reliabilities that are higher than the reliability of the system. The reliability of the column footing dictates the reliability of the system in the early life of the bridge. The column footing was assumed to have negligible deterioration relative to the rest of the bridge. Its reliability remains almost constant throughout the life of the structure and only drops due to increased live load. The drop in system reliability later in the life of the structure is due to the deterioration of the concrete slab. The pier cap is not deteriorating as quickly because the surface concentration of chlorides was not as high and only the exterior portions of the reinforcing stirrups are corroding.

Fig. 8 demonstrates that the bridge reliability depends on the series-parallel model of the system and the deterioration of its components. The component with the lowest reliability may not be the most important component and does not necessarily control the reliability of the system. Also, the most important component early in the life of the structure may not be the most important during the later periods. It is difficult to predict the reliability of the system even if the reliabilities with respect to the occurrence of all failure modes are known, and therefore, a repair strategy based solely on component reliabilities would most likely be inefficient.

The bridge system is evaluated every 2 years and is repaired whenever the system reliability $\beta_{\text {sys }}$ falls below the target level. The only component being repaired is the slab, which gets replaced at years 50 and 94 . The slab is repaired again at year 106 , but the repair does not cause the system reliability to rise above the target level, at which point some repair other than replacing the deck must be made.

The same analysis is completed for the case of Option 4 (see Table 4) for all girders and the deck as shown in Fig. 9. In this example, all nine girders and the entire deck are being replaced whenever the system reliability index falls below the target level. In fact, everything except the pier cap and column footings are being replaced. Surprisingly, this has little effect on the system reliability relative to replacing the slab. The girders and the deck are both replaced at years 50 and 94. The only difference is that the system reliability does not fall below the target level until year 108 instead of year 106. It appears that replacing the girders and the deck would be a waste of money and resources, relative to replacing the deck only.

The optimum repair strategy as a function of the desired service life extension of the bridge can be found from Fig. 10, where all feasible options and their associated costs are considered. The costs are computed using the 1996 costs listed in Table 5, discounted over time and using a discount rate of $2 \%$. The present value cost $C_{\mathrm{PV}}$, for example, of replacing the deck at year 50 is computed as

$$
C_{\mathrm{PV}}=\frac{C_{\text {rep }}}{(1+r)^{n}}=\frac{\$ 225,600}{(1+0.02)^{50}}=\$ 83,813
$$

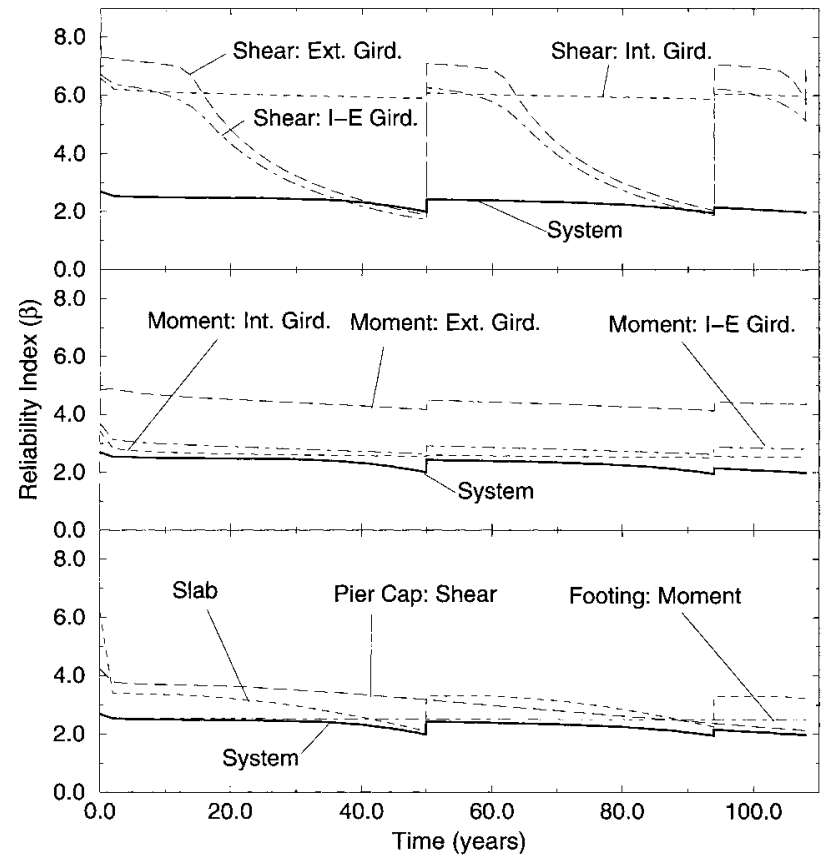

FIG. 9. All Girders and Deck Replacement Strategy (Option 4) Using Bridge System Failure Model in Fig. 3(a)

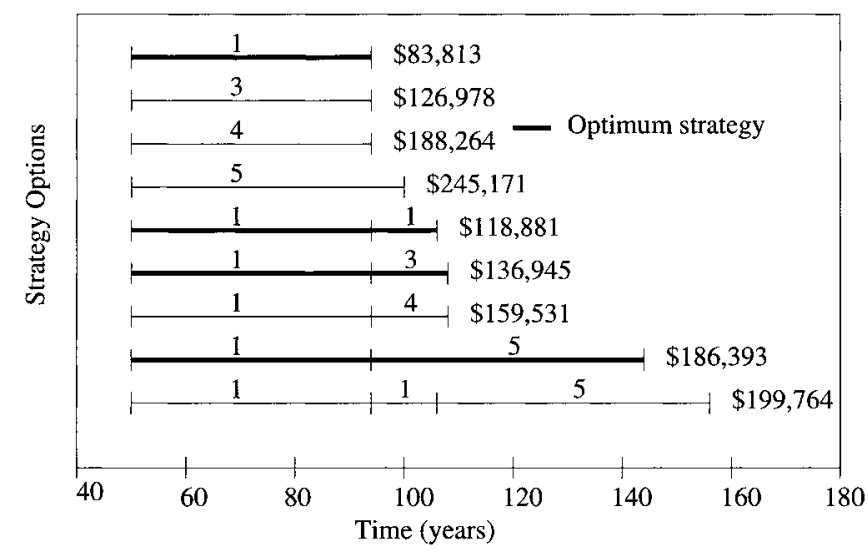

FIG. 10. Replacement Strategy Options Including Optimum Strategies Using Bridge System Failure Model in Fig. 3(a)

TABLE 5. Optimum Lifetime Repair Strategy for Bridge E-17AH Using Series-Parallel Model Requiring Failure of any Three Adjacent Girders

\begin{tabular}{c|c|c}
\hline \hline $\begin{array}{c}\text { Service life extension } \\
\text { (years) }\end{array}$ & $\begin{array}{c}\text { Optimum strategy } \\
(1)\end{array}$ & $\begin{array}{c}\text { Expected repair cost } \\
(1996 \text { US } \$) \\
(3)\end{array}$ \\
\hline $0-50$ & Do nothing & 0 \\
$50-94$ & $1 @ 50^{\mathrm{a}}$ & 83,813 \\
$94-106$ & $1 @ 50,1 @ 94^{\mathrm{b}}$ & 118,881 \\
$106-108$ & $1 @ 50,3 @ 94$ & 136,945 \\
$>108$ & $1 @ 50,5 @ 94$ & 186,393 \\
\hline
\end{tabular}

${ }^{\mathrm{a}} 1 @ 50=$ Option 1 (replace deck) at year 50.

b1@50,1@94 = Option 1 (replace deck) at year 50 followed by Option 1 (replace deck) at year 94 .

where $C_{\text {rep }}=$ cost of the repair option as shown in Table $4 ; r$ $=$ discount rate; and $n=$ number of years in the future when the repair will be made.

Fig. 10 shows that Options 1, 3, and 4 yield the same life extension (i.e., from 50 to 94 years), but for very different costs. As indicated, Option 1 is the most economical. Therefore, for subsequent interventions, Options 3 and 4 for the initial repair were eliminated from consideration. Option 2 was 


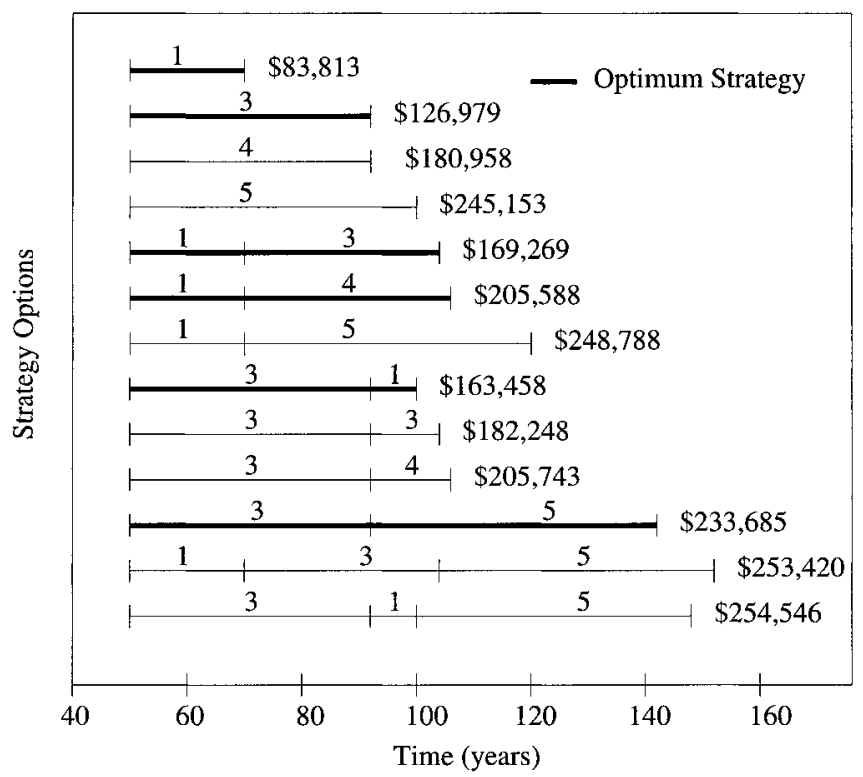

FIG. 11. Replacement Strategy Options Including Optimum Strategies Using Bridge System Failure Model in Fig. 3(b)

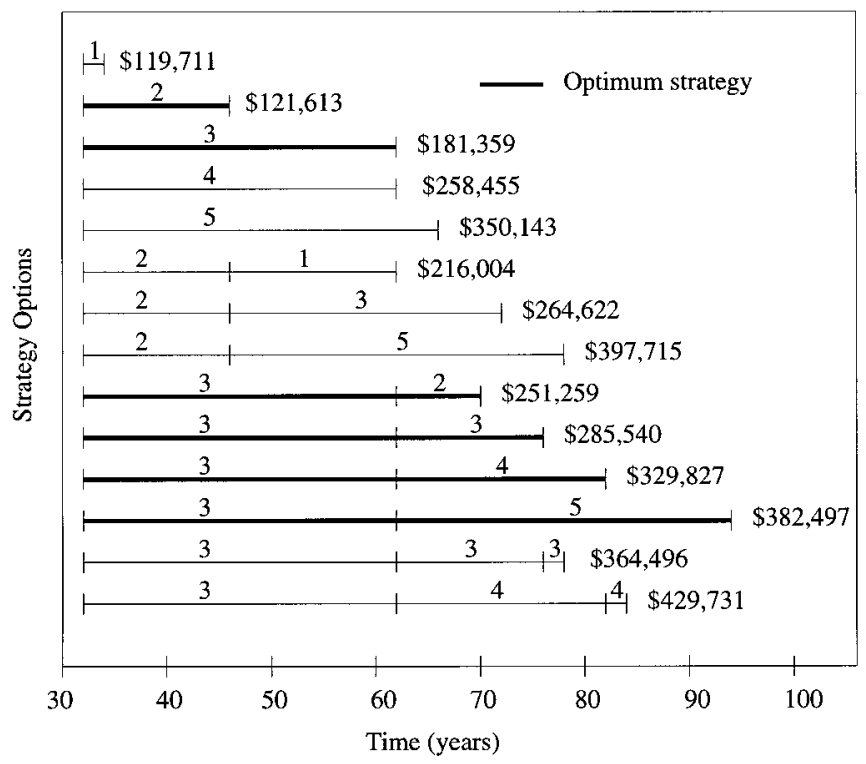

FIG. 12. Replacement Strategy Options Including Optimum Strategies Using Bridge System Failure Model in Fig. 3(c)

not considered because it did not improve the system reliability of the bridge above the target level. The process was continued until there was no choice but to replace the bridge. The optimum lifetime repair strategy based on Fig. 10 is summarized in Table 5. It is unrealistic to believe that one would choose a more expensive repair strategy just to obtain two extra years of service life (i.e., 106-108 years), but the analysis (Table 5 and Fig. 10) does reflect Option 1 at year 50, Option 3 at year 94 (1@50, 3@94) instead of Option 1 at year 50, Option 1 at year 94 (1@50,1@94) as the optimum strategy for that very small increase in the service life.

The same analysis was applied and optimum repair strategies were developed for the series-parallel bridge models shown in Figs. 3(b and c). Figs. 11 and 12 show the strategy options and the associated costs when the failure of any two adjacent girders [Fig. 3(b)] and the failure of any girder [Fig. 3(c)], respectively, resulted in the failure of the superstructure. Optimum strategies were also developed by varying deterioration rates (Fig. 13) and discount rates (Fig. 14). As expected,

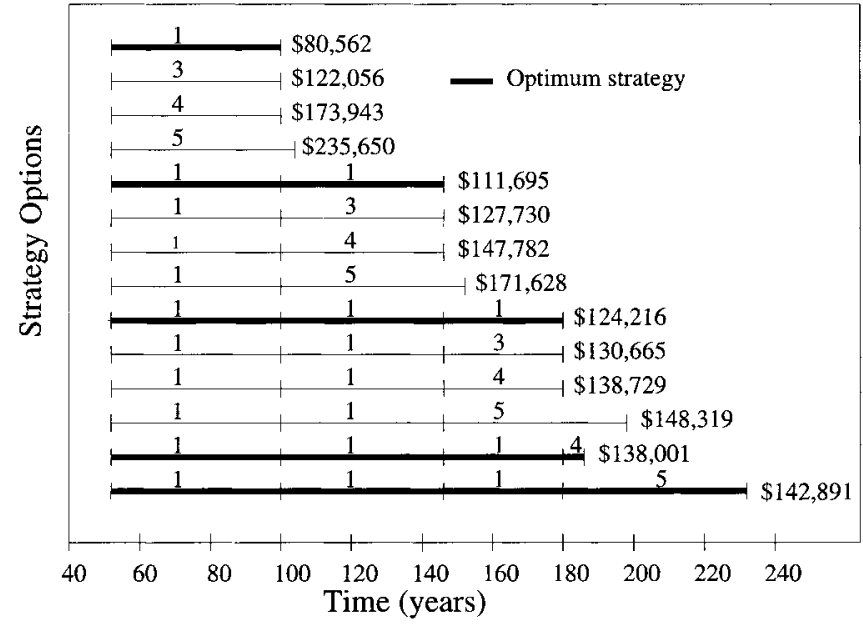

FIG. 13. Replacement Strategy Options Including Optimum Strategies Using Bridge System Failure Model in Fig. 3(a) when Mean Corrosion Rate of Pier Cap Is Halved (i.e., $0.0253 \mathrm{~mm} / \mathrm{year}$ Instead of $0.0506 \mathrm{~mm} /$ year)

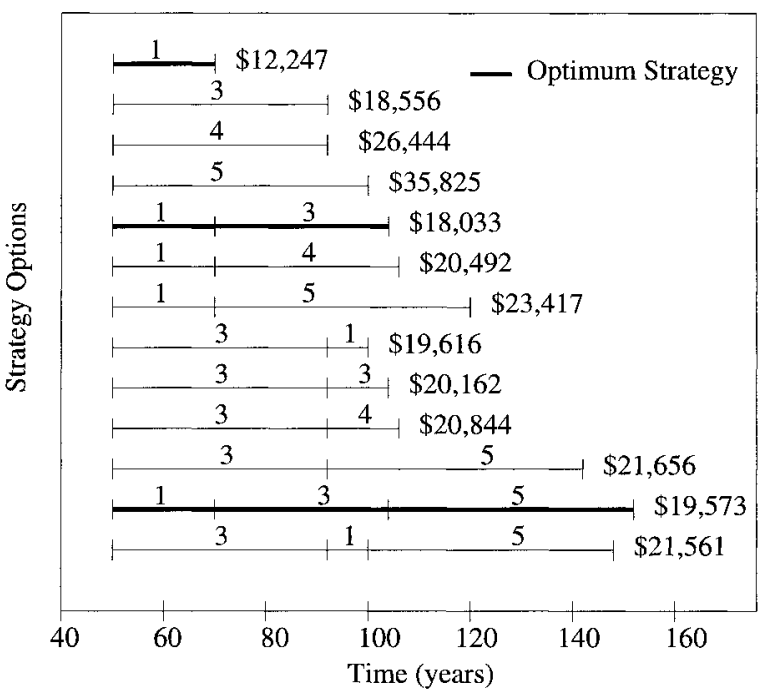

FIG. 14. Replacement Strategy Options Including Optimum Strategies Using Bridge System Failure Model in Fig. 3(b) when Discount Rate Is Tripled (i.e., $6 \%$ Instead of $2 \%$ )

increased discount rates made the later repairs in the life of the structure more attractive. The assumptions used in developing the strategy have a large effect on the outcome. Because the optimum strategy can span over a long period of time, it is essential to verify the validity of these assumptions through inspection and to modify the strategy as necessary.

\section{UPDATING OPTIMUM STRATEGY THROUGH INSPECTION}

Bridge inspection is the critically important means for verifying assumptions and updating the optimum repair strategy. Inspections provide site-specific information about parameters controlling bridge resistance and loading processes, the validity of deterioration models, and the overall condition of the bridge. Predictive strength deterioration and load models are updated with collected site-specific data. Estes (1997) described this process in detail for both visual and NDE inspections.

The most common type of bridge inspection is the biennial visual inspection required by law that provides an overall assessment of the entire bridge. The visual inspections, however, do not usually provide the relevant and detailed information 
needed to update the reliability of the bridge. Using the actual inspection data from the PONTIS (1995) Bridge Management System for Bridge E-17-AH, Estes (1997) attempted to update the system reliability of the bridge. First, a segment-based inspection (Renn 1995) was needed to identify the location of damage on the bridge. The reliability update was only possible for the girders where the condition states being evaluated were quantified numerically (i.e., percent section loss) and were relevant to the defect being investigated (i.e., corrosion in the girders). A number of assumptions were needed regarding the distribution parameters of the condition states, the linear deterioration of condition states, and the subjective uncertainty associated with the inspectors conducting the inspection. Some of these assumptions were hypothetical because there were no available data to support them.

A better means for updating the bridge reliability was a series of NDE tests, specifically targeted to provide information on the relevant defects under consideration. In this study, a thickness test of girders was chosen to reveal the amount of section loss due to corrosion on the girders. To reveal the deterioration in the slab, a half-cell potential test was chosen to determine the corrosion initiation time $T_{I}$ in the slab and linear polarization results (Clear 1992; Clemena et al. 1992) were used to determine the rate of corrosion $i_{\text {corr }}$ in the slab reinforcement slab. Estes (1997) and Frangopol and Estes (1997) demonstrated that with the results of these tests at various points in time, it was possible to update and revise the deterioration models, recompute the projected system reliability of the bridge over time, and revise the optimum bridge repair strategy.

\section{CONCLUSIONS}

1. A system reliability approach to optimizing the lifetime repair strategy of highway bridges was introduced using an existing Colorado highway bridge as an example. With accurate input, the methodology demonstrates real potential for minimizing costs while maintaining a prescribed level of system reliability. The proposed methodology accounts for uncertainty associated with the entire analysis process, failure-mode correlation, and the strength-deterioration process. The bridge is considered as an entire system rather than a collection of individual components. The system approach prevents the reliability of the entire bridge from becoming dangerously low even if all component reliabilities appear satisfactory. Similarly, repairs of individual components can be delayed if the overall reliability of the system is maintained.

2. The proposed system reliability optimization process produces an optimum lifetime repair strategy for initial planning purposes. When a plan attempts to forecast the condition of a structure over 30, 50, or even 100 years, inevitably some of the initial assumptions will be proven to not be precise. Still, a plan based on sound concepts that can be modified as assumptions are verified, is far more useful than no plan or a plan based on faulty logic. It is therefore important for the optimized plan to be updated based on inspection results.

3. There are some limitations to this study, indicating that further research is needed. The analysis has been restricted to strength-based considerations. Functionality considerations such as roadway width, clearances (horizontal or vertical), geometrical alignments, and traffic delays were not considered and will often cause a bridge to be repaired or replaced. The minimum acceptable system reliability was arbitrarily established. A formal analysis involving minimization of the expected total cost would ordinarily be required to establish the value of $\beta_{\min }$. The computations of failure costs are particularly difficult and not well established (Frangopol et al. 1997).

4. The transition from a hypothetical example to a realistic structural application requires tremendous research support. There are many factors including load and strength uncertainties, deterioration prediction models, repair options and costs, discount rates, series-parallel system modeling, and inspection capabilities that must be considered in the optimization process. Accurate models and supporting data require considerable research effort. This study is representative of the progress that is being made in applying reliability based optimization techniques to real-life bridge engineering applications.

\section{ACKNOWLEDGMENTS}

The support of the U.S. Army that allowed the first writer to pursue $\mathrm{PhD}$ work at the University of Colorado at Boulder under the supervision of the second writer is gratefully acknowledged. The partial financial support of the National Science Foundation through Grants CMS9319204, CMS-9506435, and CMS-9522166 is also gratefully acknowledged. The staff bridge inspection branch and staff design branch of the Colorado Department of Transportation are also thanked for their cooperation.

\section{APPENDIX. REFERENCES}

Chang, S. E., and Shinozuka, M. (1996). "Life-cycle cost analysis with natural hazard risk." J. Infrastruct. Sys., ASCE, 1(3), 118-126.

Clear, K. C. (1992). "Measuring rate of corrosion of steel in field concrete structures.' Transp. Res. Rec. 1211, Transportation Research Board, National Research Council, Washington, D.C.

Clemena, G. G., Jackson, D. R., and Crawford, G. C. (1992). "Inclusion of rebar corrosion rate measurements in condition surveys of concrete bridge decks.' Transp. Res. Rec. 1347, Maintenance of Highway Structures, Transportation Research Board, National Research Council, Washington, D.C.

Colorado Department of Transportation. (1994). "Maintenance management system FY 93/94 year-end report."' Denver.

Colorado Department of Transportation. (1995). "1994 Cost Data." Cost Estimates Unit, Staff Design Branch, Denver.

Estes, A. C. (1997). "A system reliability approach to the lifetime optimization of inspection and repair of highway bridges,' $\mathrm{PhD}$ thesis, Department of Civil, Environmental, and Architectural Engineering, University of Colorado, Boulder, Colo.

Estes, A. C., and Frangopol, D. M. (1998). "RELSYS: A computer program for structural system reliability analysis." Struct. Engrg. and Mech., 6(8), 901-919.

Frangopol, D. M., and Estes, A. C. (1997). "Lifetime bridge maintenance strategies based on system reliability." Struct. Engrg. Int., 7(3), 193198.

Frangopol, D. M., Ghosn, M., Hearn, G., and Nowak, A. S. (1998). "Guest editorial: Structural reliability in bridge engineering." J. Bridge Engrg., ASCE, 3(4), 151-154.

Frangopol, D. M., Lin, K.-Y., and Estes, A. C. (1997). "Life-cycle cost design of deteriorating structures.' J. Struct. Engrg., ASCE, 123(10), 286-297.

Ghosn, M., and Moses, F. (1984). "Bridge load modeling and reliability analysis." Department of Civil Engineering, Case Western Reserve University, Cleveland.

Lu, R., Luo, Y., and Conte, J. (1994). "Reliability evaluation of reinforced concrete beams.' Struct. Safety, 14, 277-298.

Nawy, E. G. (1990). Reinforced concrete, a fundamental approach. Prentice-Hall, Englewood Cliffs, N.J.

Nowak, A. S. (1993). "Calibration of LRFD bridge design code.' Final Rep., NCHRP 12-33, Department of Civil and Environmental Engineering, University of Michigan, Ann Arbor, Mich.

Nowak, A. S. (1995). "Calibration of LRFD bridge code.' J. Struct. Engrg., ASCE, 121(8), 1245-1251.

Nowak, A. S., and Yamani, A. S. (1995). "A reliability analysis for girder bridges.' Struct. Engrg. Rev., Oxford, England, 7(13), 251-256.

Nowak, A. S., Yamani, A. S., and Tabsh, S. W. (1994). "Probabilistic models for resistance of concrete bridge girders.' ACI Struct. J., 91(3), 269-276.

PONTIS; Release 3.0 User's Manual. (1995). Cambridge Systematics, Inc., Cambridge, Mass. 
Renn, D. P. (1995). "Segment-based inspection for load rating within bridge management systems,', MS thesis, Department of Civil, Environmental and Architectural Engineering, University of Colorado, Boulder, Colo.

Tabsh, S. W., and Nowak, A. S. (1991). "Reliability of highway girder bridges.' J. Struct. Engrg., ASCE, 117(8), 2372-2388.

Thoft-Christensen, P., Jensen, F. M., Middleton, C. R., and Blackmore,
A. (1997). "Assessment of the reliability of concrete slab bridges.", Reliability and optimization of structural systems, D. M. Frangopol, R. B. Corotis, and R. Rackwitz, eds., Pergamon, Oxford, England, 321328.

Zokaie, T., Imbsen, R., and Osterkamp, T. (1991). "Distribution of wheel loads on highway bridges." Transp. Res. Rec. 1290, Vol. 1, Transportation Research Board, Washington, D.C. 